\title{
Efficiency of Application of Integrated Measures to Combat Erosion with the Use of Irrigation Systems in Azerbaijan
}

\author{
Z. H. Aliyev \\ Department of Agriculture, Institute of Soil Science and Agrochemistry of ANAS, Baku, Azerbaijan
}

Received: 30-09-2020; Revised: 10-11-2020; Accepted: 20-11-2020

\begin{abstract}
Studies in the article have shown that productivity increases with improved structure. This is explained by the fact that in soils with $0.25 \mathrm{~mm}$ diameter water-resistant aggregates of $14 \%$, and grain yield is 22.2 cents/ha, while water-resistant aggregates are $8 \%$. In soils, this figure decreased to 18.4 cents/ha ( 3.8 cents/ha). It is also known that alfalfa plays a key role in improving the water-physical properties of the soil, as well as its agrochemical composition. The author's research shows that the amount of waterresistant aggregates under the clover is much higher than in the cotton fields. This can be clearly seen from the following comparison. Thus, the amount of water-resistant aggregates in $0-10 \mathrm{~cm}$ of soil in the cotton field is 4.0-18.5; while $0.5 \mathrm{~cm}$ is $6.5-11.2$ and $20-30 \mathrm{~cm}$ is $4.5-18.2$, in clover crops this indicator is 35.0; increased to 24.7 and 27.0. In addition, it revealed the accumulation of more organic and mineral substances under alfalfa cultivation. They proved this by the analysis of soil samples taken from the 1-year and 2-year plots. It was found that $1.66 \%$ humus and $0.112 \%$ total nitrogen were accumulated in the topsoil of the annual alfalfa field, while the amount of humus accumulated in the topsoil in the biennial clover field was $1.70 \%$ and the total nitrogen content was $0.150 \%$. It should be noted that the development of irrigation erosion in irrigated arable lands depends on the fact that the surface of the area is covered with a large cover. This was clearly shown by the observations. It was found that both relatively weak $(0.4 \mathrm{~mm} / \mathrm{min})$ and very $(1.4 \mathrm{~mm} / \mathrm{min}$ ) heavy rains protect clover soil from further washing. Thus, $0.4 \mathrm{~mm} / \mathrm{min}$, in heavy rains, the depth of the furrow under alfalfa is $14.4 \mathrm{~mm}, 31 \mathrm{~mm}$ at $1.4 \mathrm{~mm} / \mathrm{min}, 50.9$ and $64.2 \mathrm{~mm}$ between rows of cotton, respectively, and 78.6 and $113 \mathrm{~mm}$ along the row $6 \mathrm{~mm}$.
\end{abstract}

Key words: Aggregate composition, irrigation erosion, leveling, moisture, plowing, soil structure, surface slope

\section{INTRODUCTION}

Admittedly, the results of many fundamental and applied studies on soil erosion and the development of erosion phenomena have shown that modern research methods are inevitable and naturally always applied, but using the above-mentioned new works, through an integrated approach solution. The next stage in the field of science, where known ways of formation are carried

\section{Address for correspondence:}

Z. H. Aliyev

E-mail: zakirakademik@mail.ru out to prevent this, opens the way to experimental and applied research. All this has become as important as the demands of the day. It is characterized by urgency. It is known that there is no complete list of information on soil erosion and reactions at various administrative levels that scientists and researchers working in this field ignore visual and other reporting materials and content outside UNIVERSITY textbooks and can be of great help to authors on many scientific and applied topics. To date, the Republic has not been fully addressed. The research direction, soil mapping and erosionprevention project, related to soil erosion and 
especially irrigation erosion in the country's soils, is recommended for students and is broad and the main blocks (lines) can be offered: Soil erosion research - terminology, classification; criteria used to determine the risk of erosion; assessment and mapping of erosion-hazardous soils; mapping of eroded soils; soil erosion protection; design of anti-erosion measures; environmental, social and economic effectiveness of erosion control measures; status of research on soil erosion protection in Azerbaijan; and other countries of the world. Due to the lack of water balance in most parts of the country, the natural and climatic conditions of the republic create conditions for development and erosion, deflation, and require special, progressive methods of land, plant, land reclamation, and protection without a shortage of land. It should be noted that the main massifs suitable for the use of irrigated agricultural lands in the country are already part of 1.410 million hectares, and further expansion of arable lands is possible only due to the development of lowyielding lands and requires excessive protection of soil erosion, soil fertility. The author's monographs show soil erosion as an effect of natural and anthropogenic factors and the environment in the implementation of scientific research conducted by the Institute of Erosion and Irrigation of ANAS in the direction of research.

\section{Objectives of the study}

The objectives of the study were to study the results of monitoring to determine the degree of exposure to irrigation erosion of plain lands on the example of the Kura-Araz lowland and to develop prerequisites for its prevention.

Discussion of the course of the research and the results of the research:

\section{Surface leveling works}

As it is known, each of the irrigated arable lands of the republic has a high slope, while in the plains (Kur-Araz lowland) the slope is relatively low. In addition, most areas are also characterized by a superficial slope, and they are distinguished by the upper, middle, and lower parts of the area.
Most of these areas are uneven and rough. Such roughness causes uneven distribution of irrigation water provided for irrigation purposes to the irrigated arable land. Thus, soil moisture in the area is disturbed. In addition, in areas that do not have a smooth slope, the essential nutrients needed for plant assimilation are not the same, and thus the supply of nutrients to plants is impaired.

The above shortcomings hinder the ability of plants to obtain stable and high yields. Therefore, washing in such areas is also intensive. Therefore, it is necessary to carry out surface leveling works on irrigated arable lands. ${ }^{[1-5]}$

In general, surface leveling is divided into basic and current. Current leveling is different from preparing the soil for planting each year, and they do not require significant capital expenditures. Capital leveling works must be carried out at a time when the irrigated areas need to be thoroughly leveled. Irrigated arable lands are grouped according to their inclination to carry out works. Thus, areas with a slope of 0.001 are very few and non-sloping, areas with a slope of $0.001-0.025$ are slightly sloping, areas with a slope of $0.002-0.0075$ are moderately sloping, areas with a slope of 0.0075 to 0.002 are very sloping, 0 , areas from 02 to 0.005 are considered to be very steep, areas with $0.05-0.01$, and more are considered to be steeply patched areas. The surface slope for each irrigated area is determined by leveling. For this purpose, the landowner must contact a suitable specialist and know the slope of the land belonging to him. If the slope of the area belongs to it is more than 0.01 (1 $\mathrm{cm}$ height difference from every $100 \mathrm{~m}$ ), then in such areas it is necessary to carry out first of all capital, and then current leveling works. For this purpose, the necessary preparations must be made in advance.

For this purpose, on the basis of the geodetic plan, a plan of horizontal and vertical lines should be drawn every $10 \mathrm{~cm}$ (especially in ground leveling works) and a project of leveling works should be drawn up. ${ }^{[6-10]}$ The work plan must specify the scope of work, the areas to be cut and filled, the direction of the soil, the distance of relocation, etc., should be specified.

Scraper, bulldozer, and later special leveling mechanisms (PT-4, and PT-2,8) can be used for capital leveling, and PT-4A, PS-2,75, PD-5, etc., can be used for current leveling. In all cases, the thickness of the soil should be taken into account if 
you grow in any area. In this case, it is necessary to ensure that the layer of nutrients (humus, nitrogen, phosphorus, and potassium) necessary for the growth and development of the plant is not damaged. The cut humus layer should be used later in the fields.

At the same time, the landowner does not have the necessary capacity for both capital and current leveling, especially in areas where sowing is carried out from scratch with simple equipment (horn and iron) placed on special sowing units after the first (freezing) or second (repeated) plowing, etc., must carry out current leveling works in the direction of the site. In all cases, work should be done to ensure that the slope of the field does not exceed 0.01. In this way, first of all, the areas are significantly free from permanent and temporary ditches. Thus, it is possible to increase the length of the furrows in the inter-row cultivated areas, and the length and width of the irrigation strips in the fully cultivated areas. Thus, the development of irrigation erosion in irrigated arable lands can be significantly eliminated. Selection of water consumption: As it is known, the soil cover of our republic is different and differs in thickness. Relatively medium $(30-50 \mathrm{~km})$ and thick (more than $50 \mathrm{~cm}$ ) soils are located mainly on lowslope slopes (areas), while high-slope (up to $30 \mathrm{~cm}$ thick) soils are developed on sloping slopes. In such areas, the soils have a small contour (sometimes 10-20 ha) and are inclined, so it is not possible to carry out major leveling work there. The main purpose of irrigation in such areas should be to pay attention to the consumption of irrigation water. For this purpose, it is first necessary to determine the rate of irrigation. To do this, the depth of the active layer (in the nature of plants $n$ ), the volume of the soil, the difference between the moisture content of the soil after irrigation and the moisture content of the soil before irrigation. For this purpose, after determining the water norm, $10-15 \%$ additional water norm (evaporating, filtration, etc.) should be given to the obtained water norm. Then, it is necessary to try to irrigate in such a way that the required amount of allocated irrigation water can be converted into productive soil moisture by giving the irrigated areas in the way and form that the plant can use. However, the structure of the soil should not be disturbed, the water use factor should be high and most importantly, and the fertile soil layer should not be eroded.
Thus, in areas where irrigation water is supplied to the soil at a very high cost, the velocity of water on the surface exceeds its rate of absorption into the soil, and irrigation water forms a certain layer flow in the area. Conversely, in areas where irrigation water is supplied at low cost, its surface velocity is equal to the rate of absorption, and water supplied for irrigation is gradually absorbed into the soil during this period. As a result, the washing process does not take place.

Therefore, no conditions should be created for the destructive activity of water consumption in the furrow and strip method. In this process, the mechanical composition of the soil, its permeability, water permeability, slope of the area, etc., must be taken into account.

We must study the impact of different water consumption on the development of irrigation erosion in the fields of cotton, tobacco, winter wheat, corn, perennial grasses $\left(1^{\text {st }}\right.$ year-clover $)$, and perennial crops (apple orchards and olives), where irrigated agriculture is developing. For this purpose, non-normalized in cotton sowing areas - arbitrary flow, 1.0 and $0.8 \mathrm{l} / \mathrm{s}, 0.1$ in tobacco sowing areas; 0.2 ; 0.3 ; 0.4 ; 0.6 ; and 0.8 ; spontaneous flow in autumn wheat crops, 0.4 and 0.8 ; arbitrary flow in corn crops 0.4 and $0.81 / \mathrm{s}$, arbitrary flow in perennial grass (first clover) crops, 0.4 and $0.81 / \mathrm{s}$, and arbitrary flow in perennial crops (apple and olive), $2.0 \mathrm{l} / \mathrm{s}, 1.0 \mathrm{l} / \mathrm{s}$, and $0.5 \mathrm{l} / \mathrm{s}$ water consumption were used.

Studies have shown that the amount of washed soil varies according to the water consumption in areas with define natural conditions (mechanical composition of soils, irrigation method, length of furrows, etc.). Thus, while only $26.8 \mathrm{t} / \mathrm{ha}$ of soil was washed away by vegetative irrigation water applied 3 times due to non-normalized water (spontaneous flow) applied in cotton growing areas, the amount of washed soil due to $1.0 \mathrm{l} / \mathrm{s}$ water consumption was $19.4 \mathrm{t}$./ha, and $5.2 \mathrm{t} / \mathrm{ha}$ of soil was eroded due to water consumption of $0.8 \mathrm{l} / \mathrm{s}$. Such regularity was also typical for other crop areas.

It should be noted that the erosion resistance of the soils themselves also plays a key role in soil erosion. Thus, alluvial-meadow soils used in tobacco cultivation are more resistant to erosion than gray soils used for cotton cultivation. Therefore, the process of irrigation erosion in such soils is more intensive. 
In addition to the above, due to unregulated water use in agricultural irrigation, soils are subject to irrigation erosion, and humus and essential nutrients (nitrogen, phosphorus, and potassium), which are essential for plant growth and development, are washed away by both liquid and silt flows remain untouched.

The results of the analysis showed that the amount of humus washed by liquid flow is $0.006 \%$, the amount of humus washed by downstream is $0.79 \%$, $0.018 \%$, and $2.0 \%$, respectively, in tobacco fields, $0.033 \%$ and 2 in autumn wheat fields, respectively. $0 \%, 0.013 \%$, and $2.02 \%$ in corn crops, $0.011 \%$ and $1.22 \%$ in perennial crops. These were significantly higher than the humus and other nutrients washed in the areas regulated by the relevant plantings or where water consumption was reduced. The amount of $\mathrm{K} 2 \mathrm{O}$ in such crops is 144.6-241.0, respectively; 89.2-241.0; and fluctuated between $70.5-86.10$ and $144.5-181.3 \mathrm{mg} / \mathrm{kg}$. All this has negatively affected the growth and development of plants. Thus, while there were 18.22 cones on the trunk of a cotton plant in an area not subject to irrigation erosion, there were only 10-12 cones on a cotton bush in an area not irrigated. Or, if the height of the tobacco plant is $234 \mathrm{~cm}$ and the number of technically useful leaves on it is 54 , the height of the tobacco plant in the washed areas is $75 \mathrm{~cm}$, and the number of technically injured leaves does not exceed 17. In areas with $0.4 \mathrm{~L}$ of water per second, the height of corn ("Krasnodar-508") is $275 \mathrm{~cm}$, the number of legs on its stem is 3, the number of productive stems in winter wheat (Bozozstaya-I) is 470 , the weight of one grain is $1.9 \mathrm{~g}$. amount 51 ; the weight of 1000 grains is $45.8 \mathrm{~g}$, clover ("Azerbaijan 262 " variety) $56 \mathrm{~cm}$, while the number of stems per square meter is 473 , in areas with high water consumption and intensive irrigation erosion, the height of corn is $217 \mathrm{~cm}$, the number of legs is I, the number of productive stems in wheat is 350 , the depth of one spike is 28 , the length of one spike was $4.9 \mathrm{~cm}$, the weight of the grain in one spike was $0.8 \mathrm{~g}$, the weight of 1000 grains was $34 \mathrm{~g}$, the height of the clover was $35 \mathrm{~cm}$, and the number of stems per square meter did not exceed 416. All this leads to a decrease in the productivity of the described plants. Thus, 30.6 quintals per hectare of non-eroded cotton, 35.5 quintals from tobacco, 53.0 quintals from corn, 37.0 quintals from autumn wheat, 372.0 quintals from perennial grasses (alfalfa, and green mass), and if $70 \mathrm{~s}$ of crop is harvested from perennial crops, 17 from such eroded crops, respectively; $16.9 ; 31.5 ; 23.3 ; 141.0$; and $49.2 \mathrm{~s}$ of product were received. Thus, users are exposed to $12.4 \%$ of cotton fields each year due to irrigation erosion; 18.6 from tobacco crops; 11.5 from corn crops; 13.7 from wheat crops; 131 less crops were harvested from spring alfalfa ( $1^{\text {st }}$ year); and $20.8 \mathrm{~s}$ less from perennial crops (palmet apple). Taking into account the above, water consumption should be observed when irrigating cotton, tobacco, corn, winter wheat, alfalfa, perennial crops with furrows, and strips. This measure should be coordinated with the slope of the area, the length of the furrow, the water permeability of the soil, etc. It is better that water consumption in cotton fields should not exceed 0.8 , in tobacco and corn crops $0.6-0.8 \mathrm{l} / \mathrm{s}$, water consumption in autumn wheat and annual grass (alfalfa) crops 1.0 and 1, should not exceed $5 \mathrm{l} / \mathrm{s}$, and the width of irrigation strips should fluctuate between 3 and 5. The length of irrigation furrows in the areas where crops (tobacco, corn, and perennial crops) is grown should be adjusted according to the slope of the area. Thus, as the slope increases, the length of the furrow and water consumption should be reduced. In addition, the diameter of the dependencies in the water used for irrigation is also a key issue. Thus, water containing particles with a diameter of $0.10 \mathrm{~mm}$ (especially with a diameter of $0.15 \mathrm{~mm}$ ) is unsuitable for irrigation, but particles with a diameter of $0.10-0.005 \mathrm{~mm}$ are considered suitable.

Although such particles are suitable for improving the physical properties of the soil, such particles are low in nutrients. In contrast to the particles shown, particles smaller than $0.005 \mathrm{~mm}$ in diameter (especially $0.001 \mathrm{~mm}$ ) are rich in nutrients, but their deposition in the field is fast. In addition, the use of water with such particles deteriorates the permeability and aeration of the soil. Therefore, it is recommended to apply mineral and organic fertilizers to the fields from $0.10-0.005 \mathrm{~mm}$ diameter particles in irrigation.

Application of technical means: Azerbaijan's natural conditions and potential allow to develop irrigated agriculture by all means. Therefore, by effectively using such opportunities, it is possible to get more and higher yields from irrigated areas. It should be 
noted that despite the natural conditions in our total area, $60 \%$ of such area consists of mountainous areas. Technical means have a great role to play in expanding irrigation in areas that can be irrigated, both in the plains and in relatively mountainous areas. A number of technical means (artificial rain aggregates, sprinklers, water level and flow meters, pipes made of different materials, siphons, etc.) have been designed to mechanize irrigation in the former Soviet Union, including in our country.

These devices and equipment allow you to apply advanced irrigation methods (artificial rainfall, pulse drip irrigation, small dispersal irrigation, underground irrigation, etc.). Thus, "Fregat," "Kuban," "KSID-50," "Voljanka," "DDA-100 M," "DDA-MA," "Sigma-50," "DDN-70" and others brand rain, "KSID-10," "KSID-10A" and others designed for irrigating large and small areas such as. As a result of the application of such machines and aggregates, soil moisture reserves are provided in equal proportions, so the growth and development of plants go hand in hand. Despite all this, such technical means are not widely used in our country. It would be better if every landowner made extensive use of the technical means provided (mainly on farms) on the land allotted to him.

Application of artificial rainfall: Artificial rainfall is one of the most advanced irrigation methods and is a reliable measure to obtain high and stable yields. As a result of this method, it is possible to carry out frequent irrigation with the application of low water norms. In addition, such irrigation can be carried out in areas with difficult terrain without leveling. The areas are ditches, canals, and sazad.

Given these advantages of the method, the case-h at present, artificial rainfall is used in many countries around the world. It should be noted that research on artificial rainfall has been conducted in various soil-climatic zones of the former USSR.

In these studies, artificial rainfall has been shown to be beneficial. For example, studies in Uzbekistan have shown that the rate of water and irrigation was twice as low (520 m3/ha against $1100 \mathrm{~m} 3 / \mathrm{ha})$ in irrigated irrigation.

While the average yield of cotton for 5 years was 26.5 cents/ha in furrow irrigation, artificial rainfall was 29.5 cents/ha or an increase of $10 \%$.

The effect of artificial rainfall on cotton productivity in Azerbaijan has been studied. It was found that in contrast to the area irrigated with furrows, the productivity of cotton in the area of artificial rainfall was $2.44 \mathrm{sen} / \mathrm{ha}$.

The effect of artificial rainfall on the development of irrigation erosion compared to the furrow method in cotton and tobacco planting areas has also been studied. It was found that the onset of runoff, liquid runoff, runoff, runoff, and nutrient leaching is significantly reduced in artificial rainfall compared to furrow irrigation.

Despite such advantages of artificial rainfall, it is not widely used in the country. Taking this into account, this method should be widely used in the irrigated lands of our republic.

Artificial rainwater systems are divided into three groups: Mobile, semi-stationary, and stationary. The intensity of rain varies in machines and mechanisms, for example, "KI-50," "Rainbow" machine $0.23 \mathrm{~mm} / \mathrm{min}$, DDA-100 M 0,17 mm/min, DDN-700, 40mm/min, DYP-64 "Voljanka" $-0.27 \mathrm{~mm} / \mathrm{min}$, DM "Freqat" $-0.28 \mathrm{~mm} / \mathrm{min}$, and DF "Dnepr. It has the ability to rain at an intensity of $0.28 \mathrm{~mm} / \mathrm{min}$. To prevent soil erosion, artificial rainwater harvesting machines should be selected based on these parameters and the mechanical composition of the soil. Thus, heavy mechanical soils can use up to $0.1-0.2 \mathrm{~mm} / \mathrm{min}$, for medium mechanical soils $0.5-0.8 \mathrm{~mm} / \mathrm{min}$.

In addition, the water absorption capacity of the soil must be determined. High rainfall intensity and large diameter of raindrops cause the collapse of the soil structure, hardening of the topsoil, the formation of surface water, and silt flow. Therefore, artificial rainfall should be associated with the background of agro-technical measures (softening of deep strips, half-escape, maintenance of buffer strips, etc.).

\section{Drip irrigation}

Drip irrigation is one of the most advanced irrigation methods. In this method of irrigation, water and nutrients are combined with the help of a special device (nutrients are added to the crop water in the form of a product) and the required amount of water is given to the plants in their root systems. ${ }^{[11-13]}$ This method prevents leakage and evaporation of aquatic plants in irrigation, saves $50-90 \%$ of water compared to ASDI irrigation. The roots of the plant 
do not use extra energy to "search" for water and nutrients and as a result, a high, high-quality and abundant harvest are obtained from each hectare.

This method of irrigation is widely used in various developed countries (Israel, USA, etc.). The economic efficiency of drip irrigation is great.

A 1978 study in Bulgaria found that the yield of the Krasny Otlichny apple variety grown on selfirrigated land was 310.9 cents/hectare, while the yield on drip irrigation was 398.6 cents/hectare. The productivity of the variety was 282 and $310 \mathrm{sen} / \mathrm{ha}$, respectively.

Extensive work is being done in Poland on drip irrigation of vegetable crops. The technology of drip irrigation was developed in the former USSR, and the decision of the All-Union Council convened in 1977 on this issue recommended its application. This decision states that drip irrigation is an advanced irrigation method and can be applied in any relief conditions. By reducing water consumption and manual labor, it is possible to significantly increase crop yields. It should be noted that drip irrigation was first introduced in Azerbaijan in the fields of vegetables, grapes, and orchards. HM Huseynov and others have shown that when irrigation is applied by this method, the productivity of fruits is $20-50 \%$, the productivity of vegetables is $50-$ $100 \%$, and the productivity of grapes is $30-40 \%$ and so on increases. In addition, it saves an average of $60 \%$ of water compared to other advanced irrigation methods (artificial rainfall). Irrigation requires less labor and manpower.

Thus, while 37 people-hours were spent to irrigate one hectare of arable land per year in the method of furrow irrigation, only 2.5 man-hours were spent on drip irrigation. In addition, equipment used for drip irrigation can be installed elsewhere. This method does not require leveling the areas. Most importantly, there are no conditions for the formation of fluid and sludge flow.

Our training figures showed that in the case of conventional irrigation, $1 \mathrm{~L}$ of water contained 13.4-13.6 g/l of suspended particles, while in drip irrigation, soil washing was not observed. As a result, the productivity of drip irrigation increased by $35.7-38.5 \%$ compared to conventional irrigation. Therefore, more space should be given to irrigation in this way. In this way, irrigation can be easily carried out on the farm. For this purpose, water from sub-artesian, artesian wells and water sources should be taken and discharged into special water pipes, and from there into drippers attached to humidifying hoses. Due to the application of the process, manual labor is significantly reduced, and there is an opportunity to wash the soil.

Synchronous pulse irrigation: Favorable natural conditions of the Republic of Azerbaijan allow to meet the food needs of the people living here by all means.

As mentioned above, more than $85-90 \%$ of agricultural products are taken from irrigated areas. Such areas are mainly located in the plains. In such areas, mainly surface irrigation is applied. In irrigation carried out by this method, the soil surface and its profile are not evenly moistened, water loss is allowed.

Thus, irrigation erosion is developing in irrigated areas. In areas with a complex natural relief structure, it is not possible to apply surface irrigation methods (furrow or strip). Irrigation problems can be easily solved in such areas by applying synchronous pulsed rainfall, both in the plains and in areas with complex relief structure.

Such irrigation equipment includes pulse sprinklers, pulse drippers, and small dispersed sprinklers. It should be noted that low-intensity rainfall (synchronous mode) is more environmentally safe than other irrigation methods.

In synchronous mode pulsed rainfall, even in complex relief conditions, the process of erosion is completely eliminated. Such irrigation is carried out with "KSID-10" pulsed rain device. With such a device it is possible to irrigate areas equal to 10 ha, and sometimes more. Its main principle of operation is to work continuously. For this purpose, the signal to the water distributor regulates the operation of the pumping station.

Water enters the pipeline from the pumping station, and from there the impulse rainwater. Its subsequent operation automatically repeats and regulates rainfall. In this case, the supply of water is characterized by its duration and intensity. It also differs by three types of irrigation. The first of them is absolutely synchronous, the second is synchronous, and the third is asynchronous. In absolute synchronous irrigation, water is supplied according to the intensity of water demand with irrigation and daily cycle, and in synchronous irrigation with the 
same ton of water per day. Asynchronous is given in a broad sense, in all cases the water regime of the soil is improved, and washing is eliminated.

Soil-protective role of alfalfa: Prolonged use of soils in the same area for one plant reduces the amount of nutrients (organic and mineral) in them, deteriorates their water-physical properties. This is later evident in the productivity of agricultural crops. Therefore, to increase soil fertility and its efficient use, technological, reclamation, and organizational measures are taken in accordance with the naturaleconomic, soil-climatic conditions of the area.

All this is the basis of the agricultural system. Due to the properties of the soil and the productivity of the main crop, perennial grasses, especially alfalfa, are considered a good predecessor of all agricultural crops. As is known, they have strong and branched shaft roots. Such roots go to the depth of $0.5-1.0 \mathrm{~m}$, sometimes more, and bind soil aggregates like a "spider web." In addition, the tuber bacteria that form in its root system absorb nitrogen from the air and enrich the soil with nitrogen.

The clover's protective role is even greater. According to the literature, the root system of alfalfa accumulates up to 60 quintals of organic mass in 0-40 cm, depending on the degree of leaching of the soil within two years. This mass increases the fertility of the washed soils and helps to prevent irrigation erosion.

\section{RESULTS AND SUGGESTIONS}

As it is known, the main indicator of soil fertility is water, air, biological, and nutrient regime, which depends on the structure of the soil. Depending on the structure of Azerbaijani soils, it is fine-grained (aggregate size more than $10 \mathrm{~mm}$ ), granular-topar or macrostructure (aggregate size from $1 \mathrm{~mm}$ to $1 \mathrm{~mm})$.

Mesostructure (aggregate size from 0.25 to $1 \mathrm{~mm}$ ), microstructure (aggregate size from $0.01 \mathrm{~mm}$ to $0.25 \mathrm{~mm}$ ), and ultrastructure (aggregate size from $0.001 \mathrm{~mm}$ to $0.01 \mathrm{~mm}$ ). Of these, the most agronomically useful are only aggregates with small clusters and granular structure. They are also $0.25-1.0 \mathrm{~mm}$ in diameter.
Such structural aggregates retain their qualities (disintegration, water resistance, etc.) when used for long-term plant cultivation. The application of 3: 7 crop rotation is considered expedient. In the first scheme, cotton plantations will account for $66.6 \%$ of total plantings, $57.1 \%$ of medium-washed soils, $50.0 \%$ of heavily washed soils, and $70.0 \%$ of moderately washed soils. Accumulated fertility is sufficient for $2-3$, on moderately eroded soils 3-4, on heavily washed soils 5-6, and on moderately washed soils 6-7.

\section{REFERENCES}

1. Aliyev GA. Soils of the big Caucasus within the Azerbaijan SSR. Baku: Elm; 1978. p. 157.

2. Aliyev BH, Aliyev ZH, Aliyev IN. Problems Erosion in Azerbaijan and Said Russian Ways of its Solution. Baku: IZD-vo Zia-CPI "Nurlan"; 2000.

3. Aliev BH, Aliyev ZH. Technique and Technology of Lowintensity Irrigation in the Conditions of the Mountainous Region of Azerbaijan. Baku: Elm Publishing House; 1999. p. 220.

4. Aliev $\mathrm{BH}$, Aliyev $\mathrm{ZH}$. Irrigated Agriculture in the Mountainous and Foothill Regions of Azerbaijan. Baku: PublishingHouse "Ziyaya-Nurlan"; 2005. p. 330.

5. Aliyev BH, Aliev IN. Some Problems of Agriculture in Azerbaijan and Ways to Solve them. Baku: Ziyaya-Nurlan Publishing House; 2004. p. 572.

6. Babayev MA, Jafarov M, Aliev AG. Modern Pochennyj Cover of the Greater Caucasus. Baku: Times TDHA; 2017. p. 344.

7. United Nations Environment Programme. Biodiversity and Climate Diversity. Adjusted Gross Income, United Nations Environment; 2009. Available from: http:/www. cbd.int/doc/bioday/2007/ibd--2007booklet-01-ru.pdf. p. 987.

8. Umarov U, Karimov A, Taraz C, editors. International Center for Agricultural Research in Arid and Arid Regions (ICARDA) Irrigation Regime and Monitoring Technique. IC “AQUA"; 2002. p. 128 s.

9. Nosenko VF. Irrigation in the Mountains. Moscow: Kolos Publishing House; 1981. p. 143.

10. Markov YA. Irrigation of Collective and Household Gardens of the Agricultural Organization. Leningrad: Agropromizdat; 1989. p. 64.

11. Vernadsky VI. Works on the General History of Science. Vol. 1. Moscow: Nauka; 1908.

12. Mamedov RQ. Agrofizicheskaja Characteristics of Soil Priaraksinskoj Stripes; 1970. p. 321.

13. Shyhlinskij EM. Climate in Azerbaijan. Baku: Times TDHA; 1968. p. 341. 